\section{Minna LaAKSO \\ etunimi.sukunimi@utu.fi}

\section{Lähteet}

Genesee, Fred 1989. Early bilingual development, one language or two? - Journal of Child Language 16 s. 161-179.

Kanto, Laura - Huttunen, KertTU - LAAKso, MARJA-LEena 2013: Relationship between the linguistic environment and early bilingual language development of hearing children in Deaf-parented families. - Journal of Deaf Studies and Deaf Education $18 \mathrm{~s}$. 242-260.

Kanto, Laura, - Laakso, MarjaLeena - Huttunen, Kerttu 2015: Differentiation in language and gesture use during early bilingual development of hearing children of Deaf parents. Bilingualism. Language and Cognition 18 s. 769-788.

— painossa: Code-mixing by young hearing children of Deaf parents. - Bilingualism. Language and Cognition. DOI: https:// doi.org/10.1017/S1366728916000560.

Kortesmaa, Marketta - Heimonen, Krista - Merikoski, Hannele

- Warma, Maija-Leena - Varpe-
LA, VIRPI 2001: Reynellin kielellisen kehityksen testi. Helsinki: Psykologien Kustannus.

Lillo-Martin, Diane - De Quadros, Ronice M. - Chen Pichler, Deborah - Fieldsteel, Zoe 2014. Language choice in bimodal bilingual development. - Frontiers in Psychology 5 s. $153-167$.

Lyytinen, Paula 1999: Varhaisen kommunikaation ja kielen kehityksen arviointimenetelmä. Jyväskylä: Niilo Mäki Instituutti \& Jyväskylän yliopiston lapsitutkimuskeskus.

Petitto, Laura Ann - Katerelos, Marina - Levy, Bronna - Gauna, Kristine - Tétreault, Karine Ferraro, Vittoria 2001: Bilingual signed and spoken language acquisition from birth. Implications for the mechanisms underlying early bilingual language acquisition. - Journal of Child Language 28 s. 453-496.

Schiff, NaOmi - Ventry, Ira 1976: Communication problems in hearing children of deaf parents. - Journal of Speech and Hearing Disorders $41 \mathrm{~s}$. 848-858.

\title{
Miten sanoilla toimitaan - J. L. Austinin klassikko suomeksi
}

\section{J. L. Austin: Näin tehdään sanoilla. Harvardissa 1955 pidetyt William James -luennot. Alkuperäisteos How to do things with words 1962. Suomentanut Risto Koskensilta. Tampere: niin \& näin 2016. 186 s. ISBN 978-952-7189-05-4.}

Tieteellisen termistön vakiinnuttaminen Suomen oloihin on työlästä ja usein satun- naista. Harvemmin se on yhden ihmisen työtä, ja ensi yritykset leviävät vaivoin yksittäisestä artikkelista. Kurssikirjat, klassikoiden suomennokset sekä viime aikoina myös Tieteen termipankki ovat olleet keskeisiä termistön vakiinnuttajia. Varsinkin filosofit ovat kadehdittavan perusteellisesti ryhtyneet suomentamaan kaikkein vaativimpiakin ajattelijoita Aristoteleestä 
Kantiin ja Heideggeriin. Kielitieteessä termistön suomentaminen on ollut epäsystemaattisempaa.

Nyt suomennettu filosofi J. L. Austinin teos on koottu luentomuistiinpanoista. Se on yksi kolmesta sellaisesta luentosarjasta, joiden vaikutus viimeaikaiseen kielitieteeseen on ollut suurempi kuin monen valmiiksi hiotun teoksen. Muut kaksi ovat sveitsiläisen indogermanistin Ferdinand de Saussuren (2014 [1916]) Cours de linguistique générale, joka on suomennettu nimellä Yleisen kielitieteen kurssi, ja yhdysvaltalaisen sosiologin Harvey Sacksin vuosina 1964-1972 pitämät nauhoitetut luennot Lectures in conversation. Ne ilmestyivät litteroituina englanniksi kahtena laajana niteenä vuonna 1992 (ks. Sacks 1992), mutta tuskin niitä tullaan koskaan näkemään suomeksi. Sacksin keskeisen terminologian vakiinnuttamiseksi on kuitenkin viime vuonna suomennettu Sacksin, Schegloffin ja Jeffersonin (1974) klassikkoartikkeli A simplest systematics for the organization of turn taking in conversation. Suomennos ilmestyy Virittäjän verkkolehdessä nimellä Keskustelun vuorottelujäsennyksen perussystematiikka (tulossa 2016).

\section{Austinin luentojen vaikutus}

Austinin luennot julkaistiin 1962, kaksi vuotta hänen kuolemansa jälkeen. Tekijä ei siis voinut antaa teokselle lopullista silaustaan, ja esipuheen onkin kirjoittanut julkaisun toimittaja J. O. Urmson. Tästä syystä teos on osittain viitteellinen ja vaikeaselkoinen, jopa fragmentaarinenkin. Filosofien kielinäkemykseen Austin toi totuusehtosemantiikalle täydennykseksi pragmaattisen ulottuvuuden: lauseita voi tarkastella tosina ja epätosina mutta myös siltä kannalta, mitä niillä tehdään, ovatko ne onnistuneita vai eivät. Yhdessä filosofi H. P. Gricen kanssa, joka piti omat William James -luentonsa 1967 (ks. Grice 1989), Austin on ratkaisevasti avartanut kielellisen merkityksen ymmärtämistä: luonnollisessa kielessä kyse on paljosta muustakin kuin loogisesta semantiikasta. Kielellä paitsi viitataan tarkoitteisiin ja esitetään tosia ja epätosia väitteitä asiaintiloista myös vaikutetaan lausuman vastaanottajaan: luvataan, nimetään, pyydetään anteeksi. Lisäksi kielellä vihjataan (implikoidaan) ja edellytetään (presupponoidaan). Esimerkiksi lausuma täällä vetää implikoi, että puhuja uskoo täällä vetävän. Samalla se voi vihjaista, että ikkunat olisi tilkittävä tai hartiahuivi etsittävä. Lausuma lapseni on jo koulussa puolestaan presupponoi, että minulla on lapsi.

Austinin suppeahko teos käsittää kaksitoista 10-12-sivuista luentoa. Ensimmäisessä luennossa esitellään performatiivisen lausuman kieliopillinen muoto: kun preesensin yksikön 1. persoonan muotoinen väitelause (esim. kävelen juuri Mikonkadulla) on tietyn tapahtuman kuvaus, samanmuotoisen performatiiviverbin sisältävä lause (esim. pyydän anteeksi) on teko, samoin kuin vaikka papin edessä lausuttu tahdon tai vastaväittäjän lausuma hyväksyn työn osaksi tohtorin tutkintoa. Ero on verbeissä. Lauseilla voidaan tehdä sitovia tekoja niin arjessa kuin erilaisissa institutionaalisissa, rituaalisissa tilanteissa. Austin lähtee liikkeelle eksplisiittisistä performatiiveista, mutta käsitellyiksi tulevat myös implisiittiset performatiivit - siis sellaiset, joihin performatiivisuus on kieliopillistunut tai konventionaalistunut muulla tavoin. Niinpä esimerkiksi imperatiivi tule tänne vastaa eksplisiittistä performatiivia käsken/pyydän sinua tulemaan tänne. Yksinkertaisimmillaan primaari puheakti voi olla yksisanainen kuten Ulos! tai Seis!

Tästä nerokkaasta perusoivalluksesta kuljetaan luku luvulta kohti yhä monimutkaistuvaa kielellistä todellisuutta. Performatiiviverbejä on runsaasti, ja teoksen viimeisessä luvussa niitä ryhmitelläänkin viiteen kategoriaan. Toinen teoksessa esi- 
tetty perustava oivallus on puhetoiminnon kolmiosaisuus: lokuution, lausuman pelkän sanomisen, lisäksi toteutuu illokuutio, puheen aikaan saama tietynsävyinen toiminta sekä viimein perlokuutio eli puheen vaikutus vastaanottajaan.

Kielitieteeseen puheaktit tai niiden myötä tullut pragmaattinen näkökulma on vaikuttanut dramaattisesti $1960-$ ja 1970-luvuilta lähtien, Levinsonin (1983) mukaan laajemmin kuin mikään muu kielenkäytön teoria. Tätä ennen kielenkäytön sosiaalinen ja interpersoonainen ulottuvuus puuttuivat keskeisistä kielitieteen suuntauksista (strukturalismista ja sen edelleen kehittymistä) jokseenkin kokonaan. Tosin kieliopeissa vanhastaan esiintyvien lausetyyppien (väite, kysymys, käsky) kuvaus muistuttaa Austinin esittämien implisiittisten performatiivien kuvausta. Samoin kannattaa muistaa saksalaisen Karl Bühlerin (1934) kolmen funktion (Darstellungs-, Appel- ja Ausdrucksfunktion) ympärille rakentuva kieliteoria, joka sittemmin on vaikuttanut Roman Jakobsonin kielen funktioiden kuvaukseen. Edellä esittämästäni ilmennee kuitenkin, että Austinin kuvaus tulee lähimmäs kielenkäytön moniulotteisuutta.

Austinista ja Gricesta lähteneen pragmaattisen näkökulman ekspansiivisuus näkyy hyvin kahdessa laajasti luetussa kielitieteen perusteoksessa: paitsi äsken mainitussa Levinsonin Pragmatics-teoksessa myös jo sitä ennen Lyonsin (1977) semantiikkaa käsittelevässä suuressa synteesissä. Vuonna 1986 perustettiin kansainvälinen pragmatiikan yhdistys International Pragmatics Association (IPrA), jonka kongressit ovat vuosi vuodelta yhä suositumpia. Nyttemmin empiirinen puhutun vuorovaikutuksen tutkimus, vallankin keskustelunanalyysi, on kehittänyt kielellisen toiminnan tutkimista edelleen (esim. Drew \& Couper-Kuhlen toim. 2014; Raevaara 2016), mutta se tunnustaa kuitenkin juurikseen myös Austinin. Mitään systemaattista puheaktiteo- riaa ei Austin itse kehitellyt, vaan sellaista rakensi 1970-luvulla yhdysvaltalainen John Searle (1969). Edes termiä puheakti (speech act) Austin ei juuri käyttänyt vaan puhui etupäässä performatiiveista sekä lokutiivisista, illokutiivisista ja perlokutiivisista teoista, jotka, kuten edellä todettiin, ovat performatiivisen lausuman komponentteja.

Me pohjoismaiset aloittelevat lingvistit saimme tutustua kielioppikuvauksessa käytettyyn puheaktiajatteluun eräässä 1960-luvun kesäseminaarissa, jossa generatiivisen semantiikan johtohahmo John Ross esitteli niin sanotun performatiivihypoteesin. Sen mukaan lauseen semanttinen syvärakenne olisi kuvattavissa näin: I (hereby) $\mathrm{V}_{\mathrm{p}}$ you (that) S', suomeksi vastaavasti minä (täten) $\mathrm{V}_{\mathrm{p}}$ sinulle (että) L'. Syvärakenteessa oleva performatiiviverbi on abstraktinen eikä koskaan nouse pintarakenteeseen. Rossin oletuksen mukaan lauseen illokutiivinen sävy (illocutionary force) tulkittiin siis semanttiseksi eikä pragmaattiseksi. - Pragmatiikka kukoistaa edelleen ja on johtanut moniin uudennoksiin, mutta generatiivinen semantiikka on kuihtunut pois.

\section{Miten termejä vakiinnutetaan}

Suomessa oli 1970-luvulla orastavaa yhteistyötä, ainakin jokin yhteisseminaari, filosofien ja generatiivista kielioppia harrastaneiden lingvistien kesken. Sen koommin yhteydenpitoa ei ole tainnut olla, mikä näkyy tässä esiteltävästä teoksesta. Suomentaja ei nimittäin näytä tuntevan kieli- eikä kirjallisuustieteen pragmaattista perinnettä (esim. Hakulinen \& Karlsson 1979; Laitinen \& Rojola 1998) eikä ole arvannut etsiä yhteyksiä lähialoihin. Tästä on sikäli onnettomia seurauksia, että suomennokseen on jäänyt runsaasti ongelmia ja epäselvyyksiä. Liian monet keskeiset termit on suomennettu epäonnistuneesti - joskus jopa vakiintuneet kansainväliset oppisanat on turhaan käännetty. (Toisin päinkin on 
käynyt: käsittämättömiä ovat adverbili ja hypotetikaali.) Esimerkiksi performatiivien sanotaan olevan läpinäkyviä eikä eksplisiittisiä (kun niissä on yksikön 1. persoonassa oleva verbi: lupaan tulla), vihjattuja eikä implisiittisiä, perustavia eikä primaareja. Määrämerkitykseen vakiintunutta teknistä termiä presuppositio ei kannattaisi kääntää ennakko-oletukseksi eikä implikaatiota vaihtaa vaikeammin aukeavaksi termiksi epäsuora seuraus; onko implikaatioita edes mahdollista pitää sen enempää "epäsuorina" kuin "seurauksinakaan"? Puheaktitermi on jo niin vakiintunut, ettei sitä olisi tarvinnut kääntää puheteoksi.

Periaatteessa suomenkielisten vastineiden keksimisessä kansainvälisille, varsinkin englanninkielisille, termeille ei toki ole mitään vikaa. Monista latinapohjaisista termeistä on kuitenkin tullut lähes sivistyssanan kaltaisia, jolloin niiden kampeaminen suomeksi ei ole enää realistista tai ajattelua auttavaa. Tällainen on konventionaalisen korvaaminen uudissanalla tapaperusteinen - hauska keksintö, mutta liian konkreettisena aiheuttanee turhia mielikuvia. Harhaanjohtavampaa on suomentaa context sanalla taustayhteys. Kyseessähän on usein pikemminkin asia- tai tilanneyhteys, jopa lauseyhteys.

\section{Mitä Austin on sanonut ja tarkoittanut: onko illokuutioilla voima vai sävy?}

Kielellisessä merkityksessä on monia dimensioita: substantiiveilla on tarkoite eli referentti sekä mieli 'sense', lauseella propositionaalinen sisältö ja nyt sitten performatiivien mukana lausuman käyttömerkitys eli englanniksi force. Sanan force merkitys arkikielessä on 'voima', joka mainitaan myös sanakirjoissa sen ykkösmerkityksenä. Austin on kuitenkin tarvinnut merkitystyyppien joukkoon sanan, jolla osoitetaan lausuman asemaa (statusta) lupauksena, uhkauksena, väitteenä, kehotuksena ja niin edelleen. Tällaisen käyttö- merkityksen termiksi hän on keksinyt valita sanan force, jonka sanakirjavastineita ovat myös 'todellinen sisältö' ja 'tarkka merkitys'. Sille on aiemmin yritetty vakiinnuttaa suomenkieliseksi vastineeksi arkikielistä sanaa säry, jonka merkitys tulee lähelle 'tarkkaa merkitystä. Kun suomentaja on sen sijaan käyttänyt vastineena sanaa voima, hän on joutunut sellaiseen outouteen, että ilmaus qualifying illocutionary force merkitseekin 'ilmaisuvoiman’ määrittämistä tai täsmentämistä! Merkityksistä, pragmaattisista sävyistä tässä on kyse, ei voimasta.

Aika kohtalokasta on myös suomentaa keskeinen performatiivin ominaisuus happy 'onnistunut' luontuvaksi ja sen vastakohta unhappy 'onnistumaton' luontumattomaksi. Tämä ratkaisu voi vaikeuttaa sen keskeisen näkökohdan ymmärtämistä, että performatiivisessa lausumassa ei ole kyse todesta ja epätodesta vaan ilmauksen onnistumisesta, joka on selvemmin toiminnallinen käsite kuin luontumaton.

\section{Kustantajan vastuu}

Onko Austinin klassikko käännetty kiireessä, ilman ammattitaitoista kustannustoimittajaa, vai mistä johtuu, että huolimattomuus paistaa paitsi runsaista lyöntija kielioppivirheistä myös lukuisista ilmeisen vääristä sananvalinnoista? Esimerkiksi ritual on käännetty sanalla kaavamainen rituaalisen sijasta. Jotkin termit taas on käännetty eri tavoin eri kohdissa. Esimerkiksi utterance on toisinaan lausahdus, toisinaan taas lausuma. Act on käännetty sekä teoksi, tekemiseksi että jopa asiaksi. Austinin yhden keskeisen argumentin ymmärtäminen vaikeutuu, kun truly on käännetty sanalla totuudellisesti eikä sanalla vilpittömästi. Performatiivilausuman onnistuneisuuden ehtonahan on sen esittäjän vilpittömyys.

Englanti paistaa läpi käännöksestä monin tavoin. Englannin geneeristä we- 
muotoa ei pitäisi suomentaa me-muodolla vaan geneerisellä nollalla tai passiivilla, jotta vältytään seuraavan tyyppisiltä koomisilta kuvauksilta: "Emme pelkästään jätä [!] käyttämättä minimaalisen fyysisen teon käsitettä - -, vaan meiltä näyttäisi puuttuvan myös sellaisten nimitysten ryhmä, joilla erotettaisiin fyysinen teko sen seurauksista” (s. 103). Monet kokonaiset virkkeet avautuvat vaikeasti, ellei lukija pysty päättelemään alkutekstin mahdollista sanamuotoa. Tällaisesta otan kaksi esimerkkiä: "Yhteen pantuna tämän joukon mielet muodostavat jonkin 'sanomisen' sanan 'sanoa' koko merkityksessä' (s. 88); "Toteamus on siis altis vilpillisyyksien kompastelumuodolle" (s. 122).

Suomentajan tarkoitus on ollut kiitettävä. Hän on myös perehtynyt Austinia käsittelevään filosofiseen kirjallisuuteen huolellisesti. Itse suomennostyössä olisi kuitenkin tarvittu paitsi monipuolista kokemusta kääntämisestä myös terminologista yhteistyötä, hakeutumista naapurialojen tutkijoiden yhteyteen. Kustantaja puolestaan on vastuussa siitä, että lopputulos ei ole alkutekstin veroinen: sen pitäisi kaikesta alkutekstin vaikeudesta huolimatta olla ymmärrettävää suomea. Siihen ei ole nyt päästy.

\section{Auli Hakulinen etunimi.sukunimi@helsinki.fi}

\section{Lähteet}

BüHLER, KARL 1934: Sprachtheorie. Die Darstellungsfunktion der Sprache. Stuttgart: G. Fischer.

Drew, Paul - Couper-Kuhlen, ElizaBETH (toim.) 2014: Requesting in social interaction. Amsterdam: John Benja- mins.

Grice, PAUL 1989: Studies in the way of words. Cambridge: Harvard University Press.

Hakulinen, Auli - Karlsson, Fred 1979: Nykysuomen lauseoppia. Helsinki: Suomalaisen Kirjallisuuden Seura.

Laitinen, LeA - Rojola, Lea (toim.) 1998: Sanan voima. Keskusteluja performativisuudesta. Helsinki: Suomalaisen Kirjallisuuden Seura.

Levinson, Stephen C. 1983: Pragmatics. Cambridge: Cambridge University Press.

Lyons, John 1977: Semantics 1-2. Cambridge: Cambridge University Press.

RAEVAARA, LiIs A 2016: Toimintajaksojen rakenteet. - Melisa Stevanovic \& Camilla Lindholm (toim.), Keskustelunanalyysi s. 146-161. Tampere: Vastapaino.

Ross, J. R. 1967: Constraints on variables in syntax. Julkaisematon väitöskirja. Massachusetts Institue of Technology.

SACKS, HARVEY 1992: Lectures on conversation 1-2. Toimittanut Gail Jefferson. Oxford: Blackwell.

SaCks, Harvey - Schegloff, Emanuel A. - Jefferson, Gail 1974: A simplest systematics for the organization of turntaking for conversation. - Language 50 s. $696-735$.

__ tulossa 2016: Keskustelun vuorovaikutusjäsennyksen perussystematiikka. Virittäjä 120 (3) verkkoliite.

Saussure, Ferdinand de 2014 [1916]: Yleisen kielitieteen kurssi. Suomentanut Tommi Nuopponen. Tampere: Vastapaino.

SeArle, John R. 1969: Speech acts. An essay in the philosophy of language. Cambridge: Cambridge University Press. 